\title{
Thermal overload and insulation aging of short duty cycle, aerospace motors
}

\author{
Vincenzo Madonna, Member, IEEE, Paolo Giangrande, Member, IEEE, Luca Lusuardi, Member IEEE, \\ Andrea Cavallini, Member IEEE, Chris Gerada, Senior Member, IEEE, and Michael Galea, Senior Member, IEEE
}

\begin{abstract}
Electrical machines for transportation applications need to be highly reliable, particularly if they drive safety-critical systems. At the same time, another main requirement is represented by the significant torque density, especially for aerospace, where weight constraints are extremely stringent. For achieving high peak torque, an effective strategy consists in supplying the windings with a current greater than the rated value; thus, thermally overloading the machine for limited time periods. However, if the insulation is overheated, the machine lifetime is shortened and reliability issues can arise. This paper experimentally investigates the influence of short-time thermal overload on the insulation lifetime for low voltage, random wound electrical machines. The analysis is performed on round enamelled magnet wire coils, which are aged by accelerated thermal cycles. The obtained results are statistically processed through a two parameter Weibull distribution. According to the findings of the experimental data post-processing, a lifetime prediction model is built. This model is employed for predicting the lifetime consumption of a motor embedded into an electromechanical actuator for aerospace application.
\end{abstract}

Keywords-More electric aircraft, Electromechanical actuators, Reliability, Insulation, PMSM, Accelerated lifetime testing, Lifetime model.

\section{INTRODUCTION}

$\mathrm{T}$ HE last 15 years have seen a trend towards transportation electrification especially in automotive and aerospace sectors. For these applications, electrical machines (EMs) represent a key component for future transportation systems. In automotive, the technology readiness level is such that the internal combustion engine is successfully being replaced by high performance, traction EMs. The push towards the more

Manuscript received November 08, 2018; revised January 16 2019, and March 24, 2019; accepted April 23, 2019. This work was funded by the INNOVATIVE doctoral programme. The INNOVATIVE programme is partially funded by the Marie Curie Initial Training Networks (ITN) action (project number 665468) and partially by the Institute for Aerospace Technology (IAT) at the University of Nottingham. This work was also partially funded by the University of Nottingham Propulsion Futures Beacon through the project PF42. This work was supported by the Ningbo 3315 Innovation Team Scheme under Grant 2018A-08-C (Corresponding Author: Michael Galea)

V. Madonna, P. Giangrande, C. Gerada and M. Galea are with the Power Electronics, Machines and Control (PEMC) group, University of Nottingham, Nottingham, NG72RD, UK (e-mails: eexvm3@nottingham.ac.uk; ezzpg@nottingham.ac.uk; eezcg@nottingham.ac.uk; ezzmg@nottingham.ac.uk).

L. Lusuardi and A Cavallini are with the Department of Electrical, Electronic and Information Engineering "Guglielmo Marconi," University of Bologna, 40126 Bologna, Italy (e-mail: luca.lusuardi4@unibo.it; andrea.cavallini@unibo.it)

M. Galea is also with the School of Aerospace, University of Nottingham Ningbo China, Ningbo 315100, China. electric aircraft (MEA) is resulting in a growing number of aircraft secondary systems electrically operated [1, 2]. An example is the ever-increasing role of electromechanical actuators (EMAs). EMAs have already been proposed for primary and secondary flight control surfaces [3, 4], landing gear extension/retraction and nose wheel steering systems [5]. EMAs benefit from the noticeable flexibility typical of the electric system [3] and they allow a significant weight reduction along with higher efficiency [6] when compared to traditional hydraulic and/or pneumatic systems. However, it is still difficult today for these EMAs to achieve the same level of force/torque density performance such as those of hydraulic systems. The maximum achievable force/torque density of an EM is constrained by three factors, namely electromagnetic, mechanical and thermal limits. The electromagnetic limit is related to the magnetic saturation of the electrical steel used for manufacturing both stator and rotor cores. The mechanical limit is associated to the strength of mechanical components such as bearings and shaft. Both electromagnetic and mechanical factors can only be pushed by the adoption of high-performance materials (e.g. high permeability, low-loss soft magnetic materials, high strength bearings etc...). The maximum temperature that insulating materials can withstand (i.e. thermal class) represents the EM's thermal limit [7]. This constraint can be mitigated by an effective thermal management e.g. using forced liquid cooling [8,9]. Nevertheless, in order to avoid complex cooling methods, natural air-cooled EMs are generally preferred for EMA applications [5]. EMAs usually work with short-time duty cycles, since the EM is operating for a brief period of time with respect to its thermal time constant (i.e. the time required for reaching the $63.2 \%$ of the steady state temperature) [10]. Considering these operating conditions, an excellent torque density can be achieved by feeding the windings with higher current density. Conventional EMs are traditionally designed for a hot spot temperature always lower than that of the insulation thermal class. In fact, as per Montsinger/Arrhenius laws, every $8-10^{\circ} \mathrm{C}$ temperature increase halves the insulation lifetime [11-13]. In terms of insulation, the weakest component is represented by the turn to turn enamel layer. Indeed, insulation-related failures are generally originated by a turn to turn breakdown [14], which yields to over-temperatures that can trigger most severe failures (e.g. phase to ground short-circuits) and eventually lead to the EM outage. Although fault-tolerant designs and specific control algorithms can be implemented for safely operating the EM under electric fault condition; the availability of a tool capable of predicting the insulation lifetime consumption, might result 
beneficial for scheduling the maintenance activity and preventing the EM's performance derating. These requirements are crucial for EMs employed in safety-critical applications such as aerospace and automotive [15].

Insulation lifetime models, based on Montsinger/Arrhenius laws, are suitable for evaluating the lifetime consumption of EMs operating in continuous-duty service, where the winding temperature is mostly constant throughout the working period. On the contrary, these models show some limitations when the EM operates in short-duty service and a considerable variability in the winding temperature is observed. For this reason, the insulation lifetime model needs to be properly modified in order to include the influence of the variable temperature. A lifetime model accounting for the dynamic temperature is presented in [16], where the analysis is carried out through simulations performed on an EM for traction application. Similarly, the impact of repeated motor starts on the insulation lifetime is evaluated and quantified in [17], where the study is focused on mains fed induction motors. Lifetime models are also used for predicting the lifetime consumption of high voltage $\mathrm{AC}$ cables, when they are exposed to load cycling / thermal transients [18].

This paper analyses the effect of short-time thermal overloads on the insulation aging for low voltage EMs. Accelerated lifetime tests are performed on round enamelled magnet wire coils and their results are elaborated via the two-parameter Weibull distribution. A lifetime prediction model, developed according to the Arrhenius law and accounting for the thermal cycling (i.e. Miner law), is built employing the outcomes of the statistical study. Finally, the probability of failure and the lifetime consumption of an EM integrated into a landing gear extension/retraction EMA are estimated by means of the experimentally-tuned lifetime model.

\section{HELICOPTER LANDING GEAR ACTUATOR}

For assessing the repercussions of the short-time thermal overload on the insulation lifetime, a low voltage, aerospace EM is considered as a case-study. The selected machine drives a helicopter nose landing gear mechanism [19]. A schematic illustration of the landing gear retraction/extension mechanism is shown in Fig. 1. The system is actuated by a permanent magnet synchronous machine (PMSM) through a coupling gearbox whereas the PMSM is supplied by power electronics converters (PECs). The connection cable between PECs and PMSM is chosen as short as possible for the purpose of minimizing the voltage enhancement at the motor terminals, due to waveforms reflection [20].

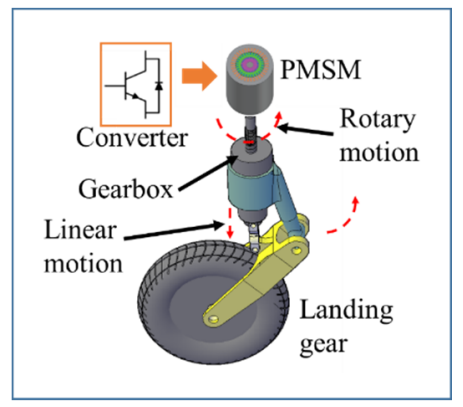

Fig. 1. Diagram of the helicopter landing gear EMA.

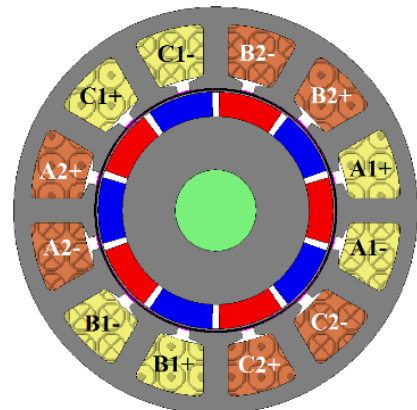

Fig. 2. Geometry and winding layout of the dual three-phase, 12 slots / 10 poles PMSM.

The machine is a surface mount PMSM with a dual three-phase winding configuration i.e. two identical set of windings are wound on the same stator core [21]. Each winding set is supplied by a separate PEC, thus the PMSM can be operated by feeding both sets simultaneously or by supplying only one of the two sets (i.e. fault-tolerant EMA architecture).

In order to avoid thermally-induced mechanical stresses, caused by mismatches in thermal expansion, the windings are not impregnated [22]. Physical separation among the phases is ensured by using concentrated windings, wound around alternating teeth [23], as shown in the cross-sectional view of the machine reported in Fig. 2. In Fig. 3, the assembled PMSM is depicted, while its main features are listed in TABLE I, alongside with the PEC parameters [24]. The landing gear EMA is only powered after taking off and just before landing. Therefore, it is activated for a short period compared to the total flight length. The time necessary for a single extension / retraction cycle is equal to $20 \mathrm{~s}$. However, for safety reasons, the EMA should be able to perform three extension / retraction cycles in a row without any cooling-down time, according to the mission profile reported in Fig. 4 [5, 25].

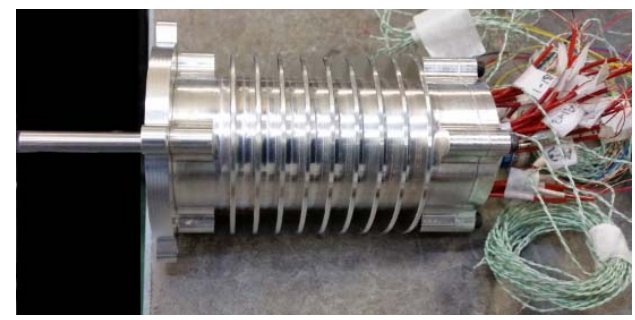

Fig. 3. PMSM driving the landing gear EMA.

TABLE I List OF DRIVE PARAMETERS

\begin{tabular}{|c|c|}
\hline Parameter & Data \\
\hline Slot number (Q) & 12 \\
\hline Pole number (2p) & 10 \\
\hline Turns per coil (nt) & 100 \\
\hline Number of strands (ns) & 1 \\
\hline Single conductor diameter $\left(D_{c}\right)$ & $0.511 \mathrm{~mm}$ \\
\hline Rated Speed $\left(\Omega_{\text {PMSM }}\right)$ & $2500 \mathrm{rpm}$ \\
\hline Rated Torque $\left[\tau_{\mathrm{PMSM}}\right]$ & $1 \mathrm{Nm}$ \\
\hline Rated Current $\left[I_{n}\right]$ & $1.1 \mathrm{~A}$ \\
\hline Stack Length [L] & $60 \mathrm{~mm}$ \\
\hline Stator Outer Diameter $\left[D_{0}\right]$ & $60 \mathrm{~mm}$ \\
\hline Copper fill factor (ff) & $50 \%$ \\
\hline Winding configuration & Concentrated \\
\hline Insulation Thermal Class & $200{ }^{\circ} \mathrm{C}$ \\
\hline Max DC link voltage & $270 \mathrm{~V}$ \\
\hline Max fundamental frequency & $208 \mathrm{~Hz}$ \\
\hline Max switching frequency & $10 \mathrm{kHz}$ \\
\hline Connection cable length & $<0.5 \mathrm{~m}$ \\
\hline
\end{tabular}




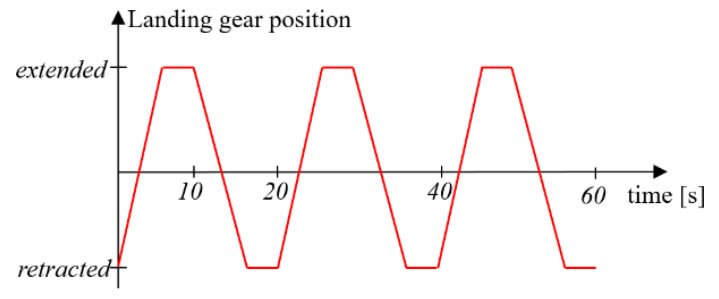

Fig. 4. EMA mission profile.

\section{A. Lumped Parameter Thermal Network}

The thermal management of the PMSM relies on a natural air cooling system through an aluminium housing equipped with radial fins.

The PMSM is tested at the rated operating condition (i.e. rated current), in order to identify the hot spot temperature and to fine-tune its lumped parameter thermal network (LPTN) which is reported in Fig. 5 [24]. Details regarding the thermal resistances and capacitances computation have been presented in [24]. For brevity reasons they are omitted in the present work. The 7-node LPTN has been implemented in a Matlab Simscape $^{\mathrm{TM}}$ environment and its fine tuning has been performed using Simulink Design Optimization ${ }^{\mathrm{TM}}$ via a sequential quadratic programming (SQP) algorithm [8]. The aim of the SQP algorithm is to minimise the error between the measured temperature and the one predicted by the LPTN. The tuned values of resistances and capacitances of the 7-node thermal network are listed in TABLE II, while the experimentally measured and LPTN-predicted temperatures, relative to the mission of Fig. 4, are given in Fig. 6. From Fig. 6 it can be observed that the LPTN can precisely estimate the temperature during both rising and falling fronts of the profile and the mismatch with the measured temperature is well below $5 \%$.

The EMA is designed for a rotorcraft which is not expected to reach altitudes higher than $\approx 10000 \mathrm{ft}$. Nonetheless, the landing gear is extracted just before the rotorcraft approaches ground level. Thus, in the performed analysis, a sea level operating pressure has been assumed.

The fine-tuned LPTN implementation represents an important step of the presented study, since it allows to accurately evaluate the PMSM's temperature profile under overload conditions.

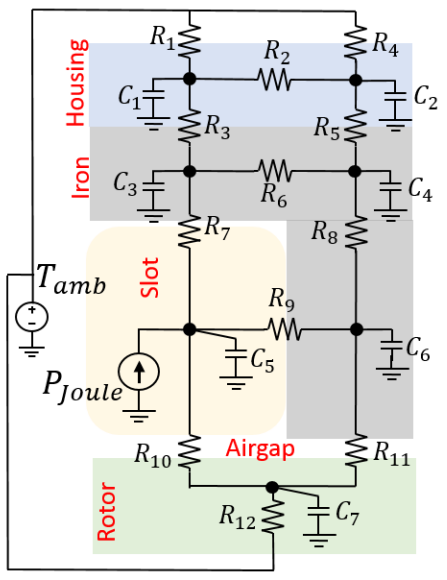

Fig. 5. 7-Node LPTN of the case-study PMSM [24].
TABLE II Tuned Values of the Resistances [K/W] And Capacitances [J/K] oF THE 7-NODES LPTN

\begin{tabular}{lll}
\hline \hline $\mathrm{R}_{1}=23.64$ & $\mathrm{R}_{7}=10.34$ & $\mathrm{C}_{1}=86.79$ \\
$\mathrm{R}_{2}=0.07$ & $\mathrm{R}_{8}=1.12$ & $\mathrm{C}_{2}=26.42$ \\
$\mathrm{R}_{3}=0.09$ & $\mathrm{R}_{9}=4.47$ & $\mathrm{C}_{3}=8.37$ \\
$\mathrm{R}_{4}=77.67$ & $\mathrm{R}_{10}=240.29$ & $\mathrm{C}_{4}=2.55$ \\
$\mathrm{R}_{5}=0.29$ & $\mathrm{R}_{11}=747.93$ & $\mathrm{C}_{5}=16.74$ \\
$\mathrm{R}_{6}=0.48$ & $\mathrm{R}_{12}=160.79$ & $\mathrm{C}_{6}=5.49$ \\
& & $\mathrm{C}_{7}=144.32$ \\
\hline \hline
\end{tabular}

The LPTN tuning procedure was performed with the PMSM unaged, that is as conventionally done in 'traditional' EMs thermal modelling. Nonetheless, insulation thermal aging can also influence the heat transfer within the machine windings [26], since the insulation physical properties are modified. Thus, future work will also address this aspect which is omitted here as it goes beyond the scope of the paper.

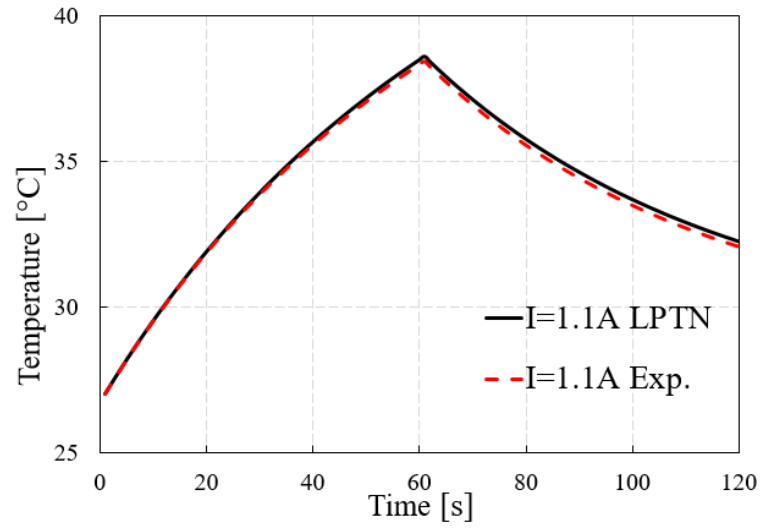

Fig. 6. Hot spot temperature profile during the EMA mission: measured (black solid line) and LPTN predicted (red dashed line).

\section{THERMAL CYCLES EXPERIMENTS}

Accelerated aging tests are widely adopted for estimating the service life of EMs [27]. During these tests, the insulation is exposed to a stress above the level expected in normal operations. The test outcome is post-processed, and the life at "normal" stress level is then extrapolated through lifetime models.

For thermal aging, the Arrhenius model, proposed for the first time by Dakin in 1947 [12], is commonly used as accelerated life model. Based on the Arrhenius law, the lifetime $L$ (in unit measure of time) of a solid insulating material operating at temperature $\theta$ can be calculated by (1), where $A$ and $B$ are parameters depending on the material properties [28].

$$
L=A \cdot \exp (B / \theta)
$$

If the thermal class of the insulation $\theta_{0}$ is known, then (1) can be rearranged as in (2) [13], where $L_{0}$ is the life at temperature $\theta_{0}$.

$$
L=L_{0} \cdot \exp \left[-B\left(\frac{1}{\theta_{0}}-\frac{1}{\theta}\right)\right]
$$

From (1) and (2), the Montsinger rule can be derived as expressed by (3), where HIC is the halving interval, which identifies the temperature increase in Celsius degrees for a corresponding $50 \%$ lifetime reduction $[11,16,17]$.

$$
L=L_{0} \cdot 2^{\frac{\theta_{0}-\theta}{H I C}}
$$




\section{A. Preliminary test and specimens' choice}

Different failure modes can be derived by thermal insulation deterioration, these include: phase to phase, phase to ground, and turn to turn failures [27]. The phase to ground and the phase to phase faults are considered the most severe electrical failure topologies, since they can cause the instantaneous EM outage unless corrective actions are promptly taken (e.g. post fault control strategy) [23]. These failure modes are usually originated by a turn to turn fault [14]. Indeed, the occurrence of a turn to turn fault results in a localised temperature hot spot caused by the increased current density in the faulted section of the coil. The temperature rise promotes the insulation deterioration leading to a fault escalation (e.g. the higher temperature quickly degrades the slot liner insulation developing a phase to ground short circuit). Considering the windings configuration of the analysed PMSM (i.e. single layer concentrated winding with alternate teeth), the phase to phase failure mode is unlikely to happen, because the phases are physically separated.

For practical reasons, accelerated lifetime tests are generally performed on motorettes representative of the original EM stator geometry. When the turn insulation aging needs to be investigated, twisted pairs can also be employed [20]. In this work, it has been decided to adopt random wound coils specimens, similar to the ones used in the case-study PMSM. This choice was also supported by the findings of a preliminary experimental test. In particular, a set of 5 motorettes, 10 twisted pairs and 10 coils wound in air have been manufactured for the preliminary test using the same class 200 round magnet wire [29] as shown in Fig. 7. The motorette represents $1 / 2$ of the case-study PMSM stator (i.e. 6 slots instead of 12). For assessing the aging of the turn to turn insulation, the motorettes are wound with two strands per coil. Further, the phase to ground insulation (i.e. slot liner) is provided by a layer of 0.13 mm Nomex ${ }^{\circledR}$ paper, with a thermal class greater than $240{ }^{\circ} \mathrm{C}$.

All the specimens (i.e. motorettes, coils and twisted pairs) are thermally aged at a constant temperature of $270{ }^{\circ} \mathrm{C}$ in a ventilated oven until the turn to turn insulation fails, as prescribed by the standard IEC 60172 [30]. The failure times have been recorded and post-processed by means of the two-parameter Weibull distribution. The results of the post-processing are summarised in TABLE III, where the mean time to failure (MTTF) of the specimens, alongside with the 95\% confidence intervals (CIs) and the standard errors are listed. For sake of completeness, the Weibull probability density plot of the specimens' failure time is shown in Fig. 8. From the results of both TABLE III and Fig. 8, it can be noted that the MTTF of the coils is considerably lower than the ones of motorettes and twisted pairs. In fact, the coils' MTTF is $42.8 \%$ and $23.3 \%$ shorter compared to the MTTF of the twisted pairs and motorettes respectively. According to these outcomes, the coils are selected as specimens for the following accelerated ageing tests.

TABLE III SPECIMENS MTTF AT $270{ }^{\circ} \mathrm{C}$

\begin{tabular}{ccccc}
\hline \hline Specimen & (lower CI) & MTTF & (upper CI) & Std error \\
\hline Twisted pairs & $306 \mathrm{~h}$ & $392 \mathrm{~h}$ & $502 \mathrm{~h}$ & $49 \mathrm{~h}$ \\
Motorettes & $266 \mathrm{~h}$ & $292 \mathrm{~h}$ & $319 \mathrm{~h}$ & $13 \mathrm{~h}$ \\
Coils & $193 \mathrm{~h}$ & $224 \mathrm{~h}$ & $260 \mathrm{~h}$ & $17 \mathrm{~h}$ \\
\hline \hline
\end{tabular}

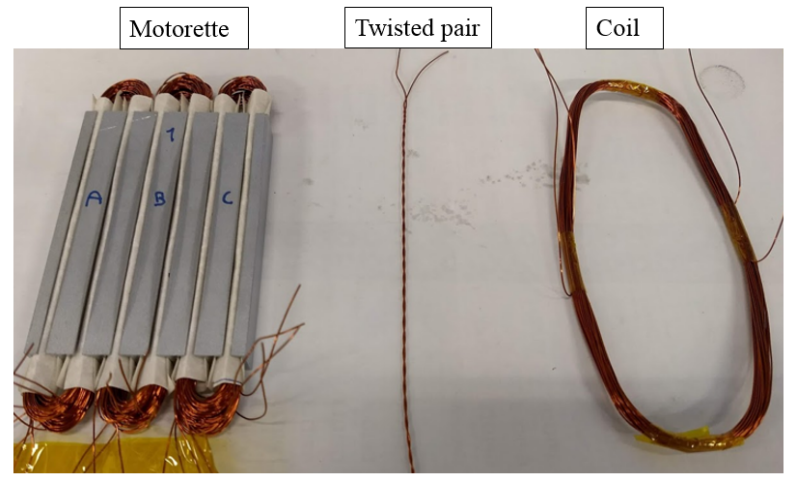

Fig. 7. Specimens used during the preliminary test: motorette (left), twisted pair (middle), and coil (right).

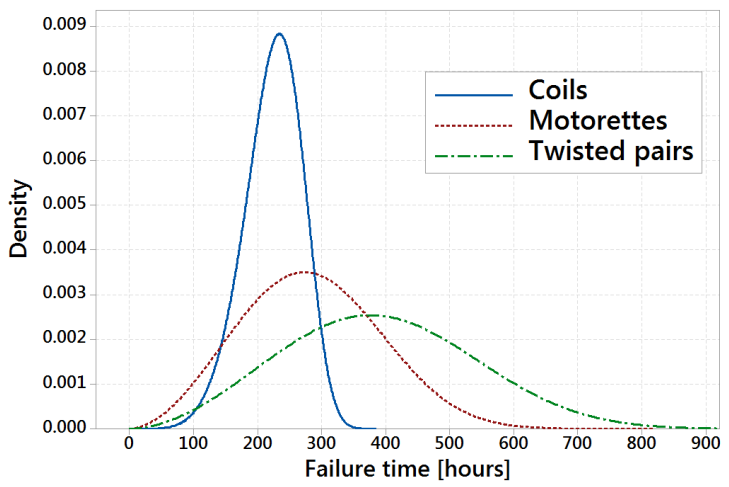

Fig. 8. Probability density plot of time to failure for the preliminary test.

This choice is justified by the convenience of building a conservative lifetime model for relying on an adequate safety margin in the lifetime consumption prediction.

As part of the preliminary test, the dissipation factor tip-up (i.e. $\Delta \tan \delta$ ) is measured for assessing the phase to ground insulation of the motorettes adopting a Megger ${ }^{\circledR}$ Delta4000. This test allows to identify if the insulation is subject to partial discharges (PDs) activity [31]. Once all the motorettes' strands insulation reached the end of life point, the phase to ground dissipation factor is measured for different voltage levels ranging from 0 to $1.75 \mathrm{kV}$ using the procedure indicated in IEEE Std 286-2000 [31]. The test outcome is reported in Fig. 9 where the motorettes' \%tan $\delta$ (mean value and variance) is plotted against the applied voltage.

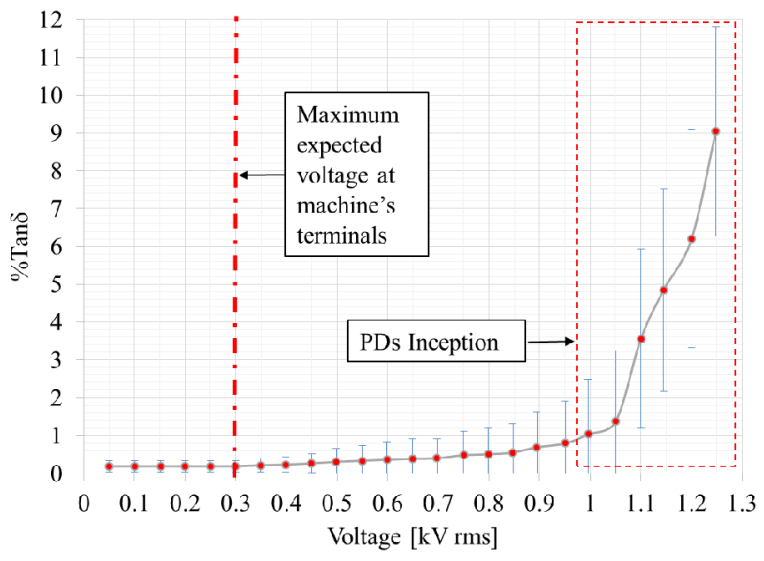

Fig. 9 Motorettes dissipation factor versus voltage measured at the end of thermal aging cycles. 
From the recorded data, it can be observed that PDs are incepted at a voltage level considerably above the worst-case voltage at the PMSM's terminals (including enhancement factors such as waveform reflections, high dV/dt etc.) [20]. Such findings were expected, due to the higher thermal class of the slot liner (i.e. $>240^{\circ} \mathrm{C}$ ) with respect to the one of the magnet wire insulation (i.e. $200^{\circ} \mathrm{C}$ ). Also, they confirm that the weakest part in the motorettes' insulation system is represented by the turn to turn insulation. Therefore, the employment of coils as specimens for the accelerated thermal aging tests, is representative of the most likely failure mode (i.e. turn to turn failure).

\section{B. Coils features}

Based on the analysis performed in the previous subsection, the chosen specimens are coils made of a class 200 round magnet wire with double enamel layer (i.e. a modified polyester base coat and a polyamide-imide over coat) [29]. The main properties of the specimens are listed in TABLE IV. For the accelerated thermal aging tests, the coils are hung to a PTFE rod and inserted into a fume hood with variable air flow-rate, as shown in Fig. 10. By regulating the flow-rate, it is possible to adjust the convection heat exchange between coils and ambient. Thus, the coils' cool-down period is varied.

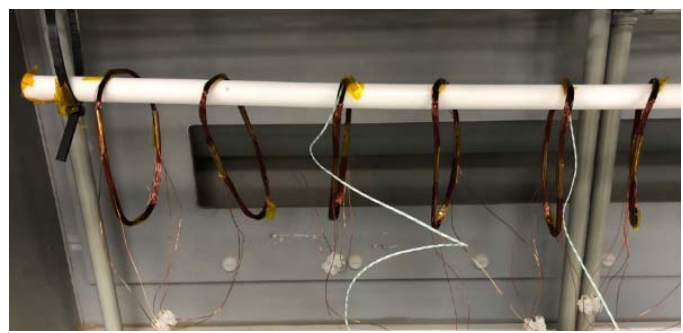

Fig. 10. Coils hung to a PTFE rod inside the fume hood.

The schematic of the experimental setup is depicted in Fig. 11. The specimens (i.e. coils) are heated exploiting the Joule effect, hence they are fed using a DC power supply. The coil temperatures are measured by means of K-type thermocouples uniformly distributed within the specimens. The acquired temperatures are elaborated by a digital signal processor (DSP), which also controls the DC power supply via the analogue interface. For aging purpose, the applied aging temperature profile is shaped by selecting the suitable DC current value and the proper air flow-rate of the fume hood. Once the specimens are hung inside the fume hood, a fixed air flow-rate is set on the extractor control board, depending on the required $\Delta \theta / \Delta t$ (i.e. a higher temperature derivative requires a higher air flow-rate). Two DC current values are then selected on the DC power supply, $I_{l}$ and $I_{2}$, where $I_{l}$ is applied during the rising portion of the temperature profile, and $I_{2}$ is applied during the falling stage. The DC power supply is controlled so that the specimens' temperature stays within the chosen limits. If a stepper temperature profile is required, then $I_{l}$ must be increased, whilst $I_{2}$ must be reduced. The flow-rate and the DC currents are selected at the beginning of tests and then maintained for the whole aging campaign as the test rig is in an environmentallycontrolled room (i.e. the ambient temperature is maintained constant throughout the aging campaign).

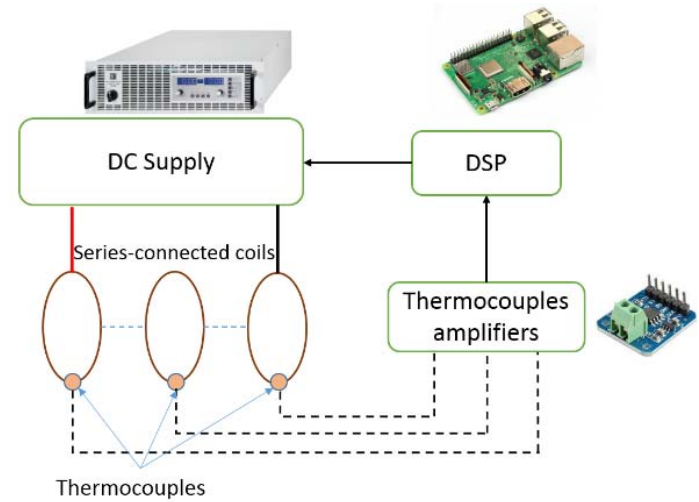

Fig. 11. Diagram of the experimental test bench.

TABLE IV COILS PARAMETERS

\begin{tabular}{cc}
\hline \hline Parameter & Quantity \\
\hline Thermal class & 200 \\
Number of turns & 20 \\
Strands in parallel & 2 \\
Copper core diameter & $0.4 \mathrm{~mm}$ \\
Average turn length & $250 \mathrm{~mm}$ \\
Number of coils per cycle & 12 \\
\hline \hline
\end{tabular}

The accuracy and the statistical validity of accelerated aging tests are largely reliant on the number of tested specimens. No recommendations are provided by the standards regarding the tests at variable temperature for low voltage coils. However, for tests at constant temperature (i.e. performed in a ventilated oven), the standards generally recommend to use at least 10 specimens per temperature cycle [30]. In the presented investigation, 12 specimens (i.e. coils) are aged for each tested temperature profile.

The performed accelerated aging tests, despite being different to those proposed in technical standards (i.e. constant temperature), are more representative for short duty cycle EMs.

\section{Aging temperature profiles definition}

Before starting the accelerated thermal tests, the aging temperature profiles are defined, according to the following constraints: 1) the duty cycles should have the same order of magnitude as the analysed application, and 2) the temperatures should be higher than the magnet wire thermal class in order to enhance the thermal stress and reduce the duration of the testing campaign. Three temperature profiles are determined, whose shape and characteristics are reported in TABLE V and Fig. 12 respectively (note that Fig. 12 is only used to introduce the nomenclature and to show the temperature profile shape, used here). These temperature profiles have a time duration (i.e. $\left.\Delta t_{\text {cycle }}\right)$ which is compatible with typical EMAs duty cycles [5, 32] and their minimum and maximum temperatures (i.e. $\theta_{\text {min }}$ and $\left.\theta_{\max }\right)$ are determined in order to purposely achieve an average profile temperature higher than the insulation thermal class. Hereafter, they are named as TP-1, TP-2 and TP-3.

At this stage, it is important to note that for random wound coils, the standards do not prescribe specific temperature profiles that must be used during accelerated lifetime tests at variable temperature. 
TABLE V Temperature Profiles Characteristics

\begin{tabular}{ccccc}
\hline \hline Temp. Profile & $\boldsymbol{\theta}_{\min }\left[{ }^{\circ} \mathbf{C}\right]$ & $\boldsymbol{\theta}_{\max }\left[{ }^{\circ} \mathbf{C}\right]$ & $\Delta \mathbf{t}_{\text {cycke }}[\mathbf{s}]$ & $\Delta \boldsymbol{\Delta} / \Delta \mathbf{t}\left[{ }^{\circ} \mathbf{C} / \mathbf{s}\right]$ \\
\hline TP-1 & 180 & 290 & 100 & 1.10 \\
TP-2 & 200 & 280 & 77 & 1.04 \\
TP-3 & 250 & 280 & 120 & 0.25 \\
\hline \hline
\end{tabular}

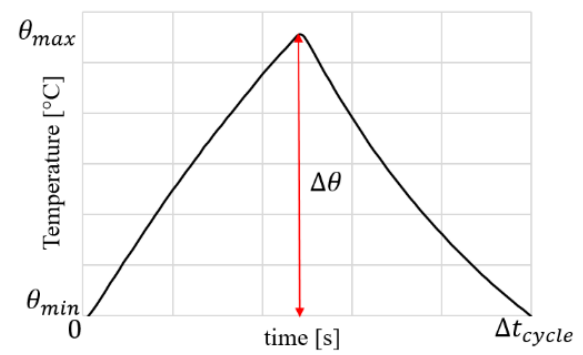

Fig. 12. Shape of the selected temperature profiles.

\section{End of life criterion}

Any property $h$ of the insulating system, which has a time trend correlated to the thermal ageing state, is called diagnostic property or ageing marker [33]. When the generic $h$ reaches a certain value, known as end point, the insulation system has arrived at its end of life. Diagnostic properties can be e.g. dissipation factor, insulation resistance, dielectric strength, weight analysis, etc...[34].

For insulation systems applied in low voltage, converter fed EMs (i.e. Type I insulation) rated at $300 \mathrm{Vrms}$ or above, the end of life criterion is given in the standard IEC 60034-18-41. In these EMs, the wire insulation consists of a thin organic film vulnerable to PDs, which are electrical discharges that only partially bridge the insulation between electrical conductors [35]. The PDs inception erodes the wire insulation leading to a failure. Thus, the PDs inception (in normal operating conditions) is assumed as end of life criterion for the turn to turn insulation of low voltage, converter fed EMs rated at $300 \mathrm{Vrms}$ or above. As earlier mentioned, the case-study PMSM is powered by a PEC with 270 V DC link voltage. Since its rated voltage is below $300 \mathrm{Vrms}$ and the connection cable between PMSM and PEC is reasonably short $(<0.5 \mathrm{~m})$, it has been decided to utilise a different end of life criterion, because the PMSM is not expected to experience PD activity. The selected end of life criterion is the AC electric withstand test (also called AC Hipot test), which is a pass/fail test consisting in applying $500 \mathrm{~V}, 50 \mathrm{~Hz}$ AC voltage for one minute. The specimen fails if a dielectric breakdown is detected during the $\mathrm{AC}$ voltage application (i.e. tripping of the Megger generator). Thus, the considered diagnostic property (which degrades as the thermal aging accumulates) is the turn to turn insulation dielectric strength. This voltage level (i.e. $500 \mathrm{~V}$ ) is well above the expected turn to turn voltage faced by the EM, thus a conservative approach is adopted. For testing the turn to turn insulation, the $\mathrm{AC}$ voltage is applied between the two parallel strands (i.e. two parallel sub coils) composing the coil. If the specimen fails the AC Hipot test (i.e. the insulation does not resist the $500 \mathrm{~V} \mathrm{AC}$ voltage and the end of life occurs), it is removed from the experiment. The specimen's time to failure is calculated as the sum of the total thermal exposure hours minus the duration of half cycle (i.e. the end of life is assumed to be occurred at half of the last thermal cycle) [30]. For the sake of clarity, the testing procedure flow diagram is reported in Fig. 13, while Fig. 14 shows a coil after 10 aging cycles, together with an unaged coil.

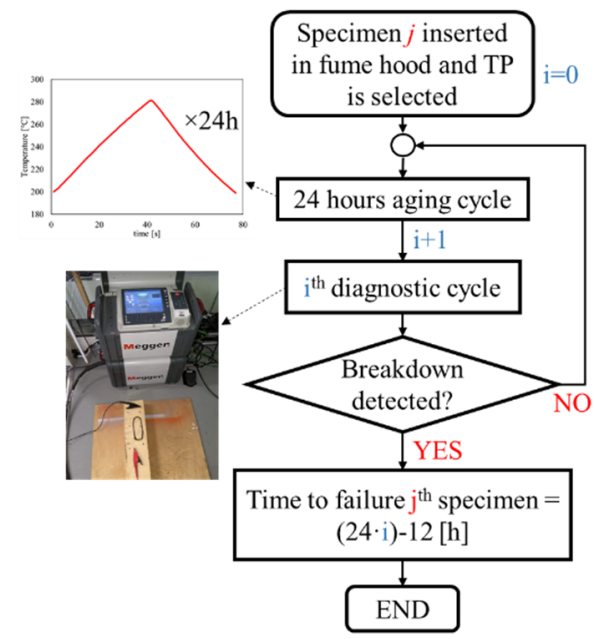

Fig. 13. Flow diagram of the testing procedure.

Looking at the aged coil (right-hand side of Fig. 14), it is possible to observe the colour change of the enamel coating caused by the overheating. In addition, some of the specimens were submitted to a visual screening using an optical microscope, prior and after the thermal cycles. In certain cases, cracks were noted on the enamel coating at the end of cycle, as proven by the enlargement in Fig. 15.

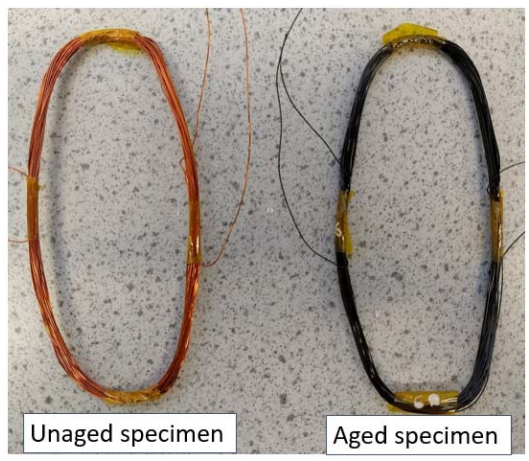

Fig. 14. Comparison between unaged (left) and thermally aged (right) specimens.

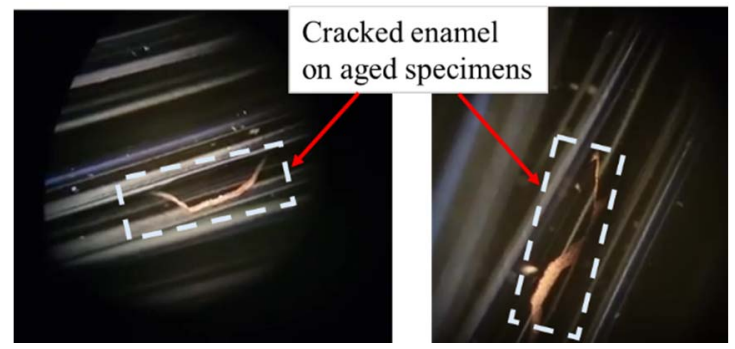

Fig. 15. Optical microscope analysis of thermally aged specimen.

\section{RESULTS POST-PROCESSING AND DISCUSSION}

\section{A. Weibull distribution}

The two-parameter Weibull distribution has been used for post-processing the time to failures experimental data. The Weibull cumulative distribution function can be described as in 
(4), where $t$ is the time to failure, $\alpha$ is the scale parameter and $\beta$ is the shape parameter.

$$
F(t)=1-\exp \left[-\left(\frac{t}{\alpha}\right)^{\beta}\right]
$$

In particular, $\alpha$ is the $63.2 \%$ percentile of time to failure, while $\beta$ represents the inverse of the data scatter, which is proportional to the variance of the time to failures [36].

For estimating $\alpha$ and $\beta$, the recorded time of failure data are rearranged in ascendant way, whereas (4) is linearized by taking the natural logarithm twice, as expressed in (5), where $t_{i}$ is the $i^{\text {th }}$ time to failure.

$$
\ln \left[\ln \left(\frac{1}{1-F\left(t_{i}\right)}\right)\right]=\beta \ln \left(t_{i}\right)-\beta \ln (\alpha)
$$

As consequence of the linearization, (5) is the general equation of a straight line having $\beta$ as gradient (i.e. slope of the straight line) and $\beta \ln (\alpha)$ as intercept on the y-axis. For sake of clarity, (5) is rewritten as in (6).

$$
Y\left(t_{i}\right)=\beta \ln \left(t_{i}\right)-\beta \ln (\alpha)
$$

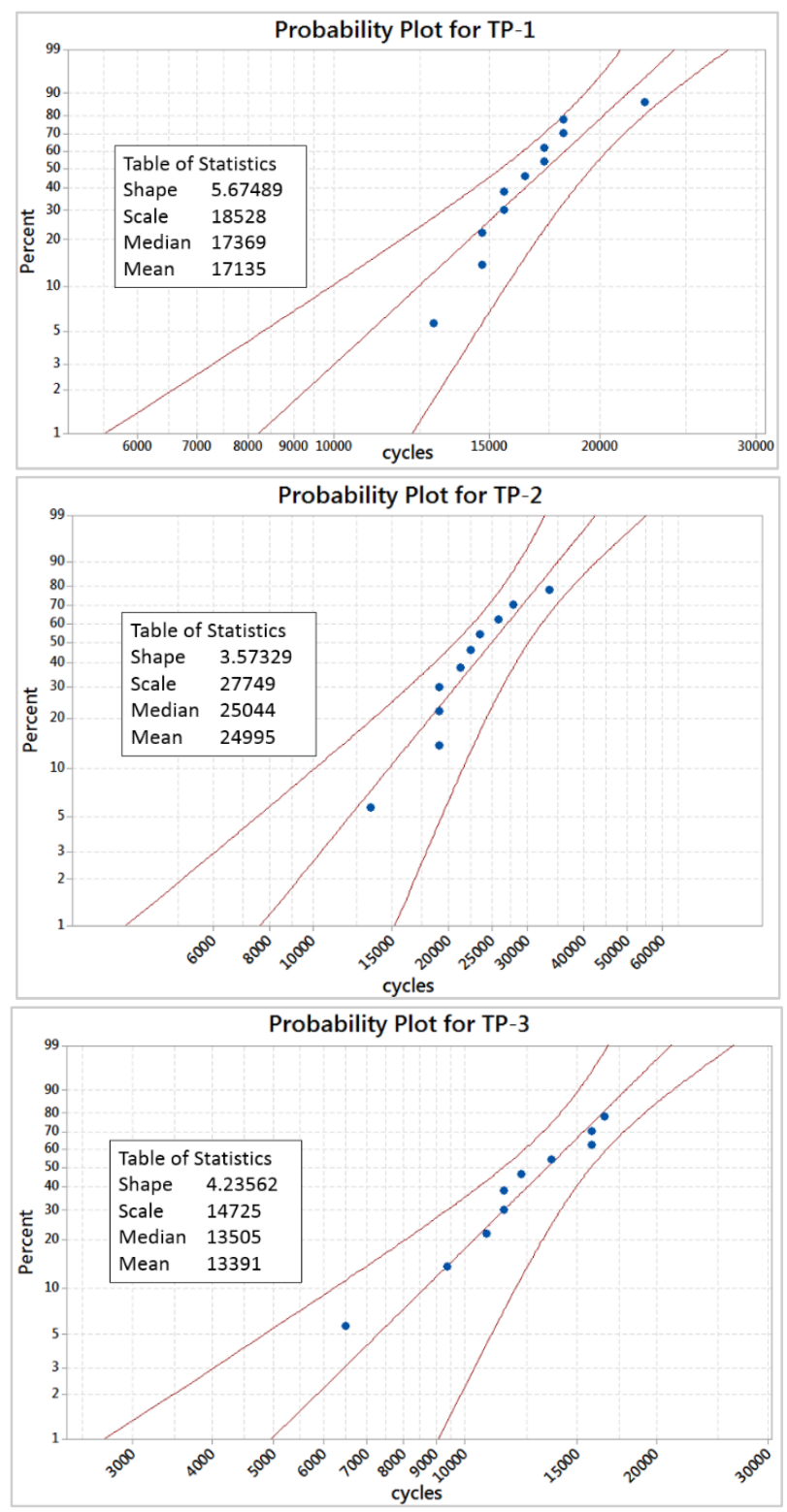

Fig. 16 Weibull probability plot for TP-1 (top sub-plot), TP-2 (middle sub-plot) and TP-3 (bottom sub-plot).
The Weibull cumulative distribution function $F\left(t_{i}\right)$ at the time to failure $t_{i}$ is evaluated using the median rank estimator, which is given by Bernard's approximation (7), where $n$ is the sample size (i.e. the number of specimens) [37].

$$
\hat{F}\left(t_{i}\right)=\frac{i-0.3}{n+0.4}
$$

Thus, by plotting $Y\left(t_{i}\right)$ versus $\ln \left(t_{i}\right)$, it is possible to obtain $\alpha$ and $\beta$ through a linear regression.

The Weibull probability plots with $95 \%$ CIs for the three analysed temperature profiles, are presented in Fig. 16. The probability plots show a good fit with the Weibull distribution.

Finally, an overview of the statistical analysis outcomes is provided in TABLE VI, where the MTTF (i.e. mean number of cycles to failure) and the $95 \% \mathrm{CI}$ are listed for the tested aging temperature profiles.

TABLE VI MTTF For THE ANAL YSED TEMPERATURE PROFILES

\begin{tabular}{ccccc}
\hline \hline Temp. Profile & (lower CI) & MTTF & (upper CI) & Std error \\
\hline TP-1 & 15256 & 17135 & 19246 & 1015 \\
TP-2 & 20745 & 24995 & 29931 & 2298 \\
TP-3 & 11488 & 13391 & 15600 & 1047 \\
\hline \hline
\end{tabular}

\section{B. Discussion}

The lifetime model based on the Arrhenius equation is implemented in Matlab ${ }^{\circledR}$ environment. In order to take account of the thermal cycling, a popular tool for life inference of devices under time-varying stresses has been implemented: the cumulative damage law of Miner [30].

The first step consists in dividing the entire time pattern into infinitesimal intervals, ranging from a generic time instant $t$ to a subsequent time $t+d t$, so that within every $d \theta$, temperature can be taken as constant and equal to the corresponding instant-value of transient temperature, $\theta_{i}(t)$. Hence, the fraction of life lost by the wire insulation, during a given $d t$ within $\Delta t_{i}$, can be written like in (8), where $L\left[\theta_{i}(t)\right]$ is the insulation life at constant temperature $\theta_{i}(t)$ [18].

$$
d L F=\frac{d t}{L\left[\theta_{i}(t)\right]}
$$

Hereafter, the quantity $d L F$ will be named 'loss of life fraction'. Therefore, the loss of life fraction at each cycle, $L F_{\text {cycle }}$, is given by (9).

$$
L F_{\text {cycle }}=\int_{0}^{\Delta \mathrm{t}_{\text {cycle }}} d L F=\int_{0}^{\Delta \mathrm{t}_{\text {cycle }}} \frac{d t}{L\left[\theta_{i}(t)\right]}
$$

For the sake of clarity, a graphical explanation regarding the computation of the loss of life fraction is shown in Fig. 17.

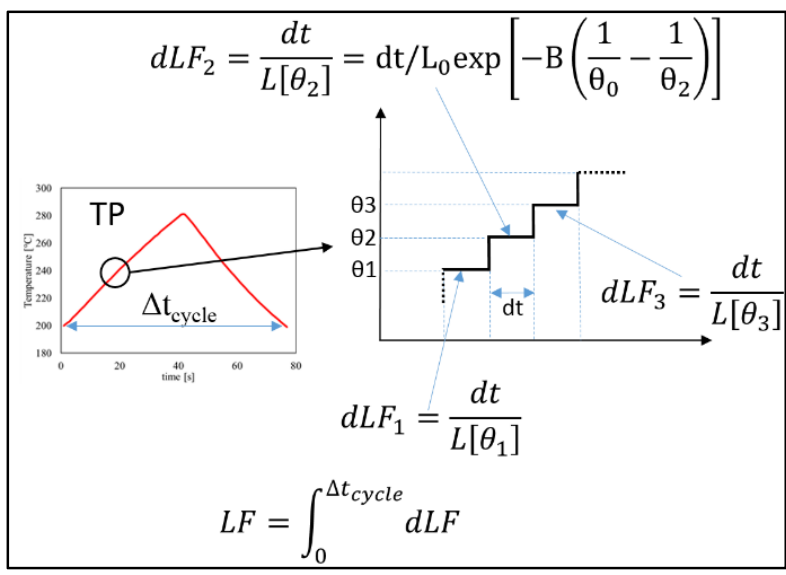

Fig. 17 Computation of the loss of life. 
From the datasheet [29], the insulation of the used wires shows an insulation life of 20000 hours at $222^{\circ} \mathrm{C}$, according to IEC 60172. For the enamel insulation under test, $B$ is equal to $24778 \mathrm{~K}$. This value is determined according to (10) where $\theta_{0}=(273+222), L_{\theta 0}=20000$ and $\theta_{\mathrm{k}}$ is a generic temperature, whose corresponding lifetime on the Arrhenius curve is $\mathrm{L}_{\theta \mathrm{k}}$.

$$
B=\frac{\ln \left(L_{\theta_{k}} / L_{\theta_{0}}\right)}{\frac{1}{\theta_{k}}-\frac{1}{\theta_{0}}}
$$

By imposing $\mathrm{L}=\mathrm{L}_{0} / 2$ in (2) and rearranging as in (11), the temperature increment for which the lifetime is halved, $\theta_{0.5}$, is then calculated. Therefore, the halving interval, (HIC in (3)), calculated according to (12) is equal to $7.1^{\circ} \mathrm{C}$.

$$
\begin{gathered}
\theta_{0.5}=\left[\frac{\ln (0.5)}{B}+\frac{1}{\theta_{0}}\right]^{-1} \\
H I C=\theta_{0.5}-\theta_{0}
\end{gathered}
$$

Determined the Arrhenius equation's parameter $B$, there are two possibilities. The first one is applicable when the exact temporal profile of the temperature is known (as in the presented study). In this case, the single period can be divided into sub periods (rise and fall of temperature) and interpolated in both separately so as to obtain two polynomial functions of the second order to be inserted in the integral that appears in (9). Following this approach, (9) can be rewritten as in (13), where $t_{i n v}$ is the instant at which the derivative of the temperature in time reverses its sign. The interpolating functions $\tau_{1}(t)$ and $\tau_{2}(t)$ are expressed in (14), where $\tau(t) \equiv 1 / \theta_{0}-1 / \theta(t)$.

$$
\begin{gathered}
L F_{c y c l e}=\int_{0}^{t_{i n v}} \frac{1}{L_{0}} \exp \left(B \tau_{1}\right) d t-\int_{t_{\text {inv }}}^{\Delta t_{c y c l e}} \frac{1}{L_{0}} \exp \left(B \tau_{2}\right) d t \\
\tau_{1}(t)=a_{1} t^{2}+b_{1} t+c_{1}, \quad t \in\left[0, t_{i n v}\right] \\
\left.\left.\tau_{2}(t)=a_{2} t^{2}+b_{2} t+c_{2}, \quad t \in\right] t_{i n v}, \Delta t_{c y c l e}\right]
\end{gathered}
$$

Alternatively, the second possibility results suitable when only the data relative to the temperature range and total cycle duration are available. This approach allows to make a rough evaluation by assuming constant the gradient, which might be an assumption not too far from reality in many cases. In particular, $\beta$ can be defined as given in (15), where $\Delta \tau=\tau_{\max } \tau_{\min }=\tau\left(\theta_{\max }\right)-\tau\left(\theta_{\min }\right)$.

$$
\beta \equiv \frac{d \tau}{d t} \cong \frac{2 \Delta \tau}{\Delta t_{c y c l e}}
$$

Hence, by making a change of variable and replacing (15) in (9), the loss of life fraction at each cycle can be expressed as in (16).

$$
L F_{\text {cycle }}=\frac{\Delta t_{\text {cycle }}}{L_{0} B \Delta \tau}\left(e^{B \tau_{\max }}-e^{B \tau_{\min }}\right)
$$

Once the loss of life fraction per cycle, $L F_{\text {cycle }}$, has been determined, regardless of the chosen algorithm, it is sufficient to impose the following equality to obtain the theoretical number of cycles to failure, $K$ :

$$
K=1 / L F_{\text {cycle }}
$$

In alternative, the total life, $L_{t o t}$, of the cyclically stressed insulation can also be calculated:

$$
L_{\text {tot }}=K \Delta t_{\text {cycle }}
$$

Table VII summarises the data obtained with the model described, using both (13) (referred to as $K_{\text {fine }}$ ) and (16) (reported as $K_{\text {rough }}$ ), using the measured temperatures as the model input. The relative errors $\varepsilon_{\text {fine }}$ and $\varepsilon_{\text {rough }}$ are computed with respect to the MTTF values presented in TABLE VI (e.g. $\varepsilon_{\text {fine }}$ for TP-1 is calculated as $\left.\left(K_{\text {fineTP-1 }}-M T T F_{T P-1}\right) / M T T F_{T P-1}\right)$. As it can be seen, the error is by no means negligible. However, this should be considered as a first attempt at modelling and further experimental measures are needed for possible validation or not. In fact, in the first instance it can be objected that the final temperature of the different profiles may be too high, giving rise to local phenomena of glass transition of the polymer and, therefore, to consequent intrinsic changes in the mechanisms of thermo-mechanical aging of the material.

In conclusion, by postponing the final verification of the model for later work, it can be used for a rough estimate of working cycles that can support the isolation of an EMA under temporary overloads. On the other hand, it can also be observed that the estimate would be conservative, as long as the gradient is low (below $1^{\circ} \mathrm{C} / \mathrm{s}$, see Table V).

\begin{tabular}{ccccc}
\multicolumn{4}{c}{ TABLE VII ResUlTS FROM ARRHENIUS/Miner MODELLING } \\
\hline Temp. Profile & $\boldsymbol{K}_{\text {fine }}$ & $\boldsymbol{\varepsilon}_{\text {fine }}$ & $\boldsymbol{K}_{\text {rough }}$ & $\boldsymbol{\varepsilon}_{\text {rough }}$ \\
\hline TP-1 & 13947 & -0.19 & 17117 & 0 \\
TP-2 & 28822 & 0.15 & 35263 & 0.45 \\
TP-3 & 9087 & -0.32 & 8784 & -0.35 \\
\hline
\end{tabular}

V. LIFETIME MODEL - STUDY CASE APPLICATION

The developed lifetime model is employed for predicting the lifetime consumption of the coil insulation, when exposed to operating cycles leading to temperatures above the magnet wire thermal class. The investigation is performed considering the PMSM presented in Section II and the fine-tuned LPTN reported in Fig. 5 is used for determining the hot spot winding temperature profile, in case of thermal overload. For this purpose, three consecutive EMA extension/retraction cycles are performed (i.e. $60 s$ operating time, as in Fig. 4), by suppling the PMSM with a current 4 times higher than the rated one. Compared to conventional operations, the PMSM overload is purposely overstated for enhancing the thermal stress. The LPTN-estimated temperature profile, when thermally overloaded, is depicted in Fig. 18. Regarding Fig. 18, the following comments can be made:

1. The starting temperature is set to $70{ }^{\circ} \mathrm{C}$ (i.e. worst-case scenario for aerospace applications) [32, 38, 39];

2. Temperatures below the insulation thermal class (i.e. $200{ }^{\circ} \mathrm{C}$ ) are assumed to give a minor contribution to the thermal aging. Thus, they are neglected in the upcoming analysis.

Taking into consideration the above comments, the input temperature profile of the lifetime model is selected, as the one highlighted by the red dashed box in Fig. 18 (i.e. temperature trend from $28 \mathrm{~s}$ to $82 \mathrm{~s}$ and above $200{ }^{\circ} \mathrm{C}$ ) and marked with TP-EMA.

In Matlab ${ }^{\circledR}$ environment, the lifetime model receives the TP-EMA (i.e. temperature versus time), as input, and predicts the resulting loss-of-life fraction based on (13). Subsequently, the number of cycles to failure is determined by using (17). For TP-EMA, the lifetime model results are given in Fig. 19, where the predicted loss of life $L F_{E M A}$ occurring during a single time period $\triangle t_{E M A}$ is plotted. In addition, the corresponding number of cycles to failure $K_{E M A}$, provided by the lifetime model, is equal to 53,689 . 


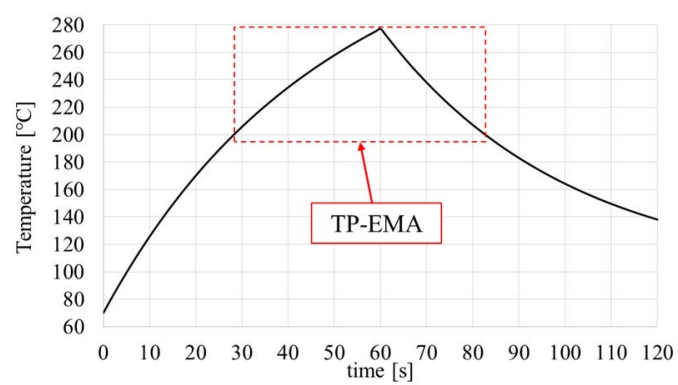

Fig. 18. PMSM LPTN estimated temperature profile during the EMA mission under thermal overload conditions.

Assuming the worst-case scenario represented by two EMA mission profiles per flight (take-off and landing), where each of them lasts 1 minute (as in Fig. 18), the first insulation failure (due to thermal aging) is expected after 26,844 flights. It is important to point out that the proposed lifetime model is built considering the MTTF. Nonetheless, different percentiles of the Weibull distribution can be adopted. In order to double check if the proposed lifetime model provides reasonable results, data regarding the actual time of failure need to be available. However, winding failure databases for electrical machines employed in EMA applications (i.e. electrical machines operating with intermittent duty) are still not readily available, due to the relatively recent adoption of EMA technology in actual applications. Therefore, to ensure feasible degradation, then, for the considered case-study, the thermal boundaries of the PMSM have been pushed considerably above the thermal class limit.

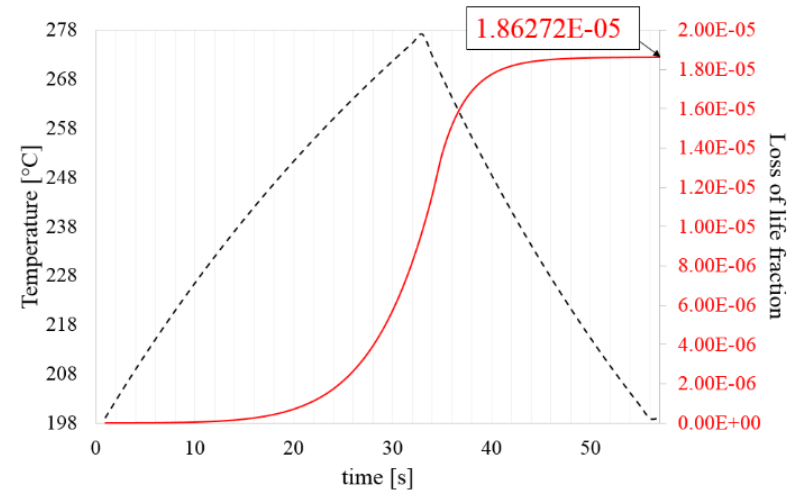

Fig. 19. Predicted loss of life (red solid line) resulting from the TP-EMA (black dashed line) application.

It is also worthy to remark that the turn to turn insulation failure does not imply an EMA out of service. EMs for safety-critical applications are designed with multiple level of redundancy, in order to operate even during severe fault conditions [39]. In this case a dual three-phase configuration has been adopted. Hence, the EMA mission can be safely completed, despite a turn to turn insulation failure, without compromising the helicopter flight performance. However, the PMSM needs to be replaced/rewound afterwards, for avoiding the escalation of the turn to turn failure into more severe faults, as previously discussed. The presented lifetime model, which is able to predict the number of flights/hours before service, is convenient for scheduling the maintenance operations. This will improve the availability of the EMA fulfilling one of the main requirements demanded by the MEA initiative. Another perceived advantage is that the developed model can be used as a tool for electrical machines designers, at the preliminary design stage (knowing the operating duty-cycle) for performing a trade-off analysis between power density and lifetime.

\section{CONSIDERATIONS ON THE PRESENTED ANALYSIS}

Throughout the analysis carried out in the previous sections, the thermal stress is accounted as the only factor contributing to the insulation aging. However, several other aging factors promote the insulation lifetime shortening. Among them, the most relevant (apart from the thermal one) are the electrical, mechanical and environmental stresses. As already mentioned, thermally induced mechanical stresses, given by mismatches in thermal expansion can also compromise the insulation lifetime in short duty cycle motors [22].

For EMs operating below $300 \mathrm{Vrms}$, the electrical aging is generally neglected, since the voltage across the insulation is below the partial discharge inception voltage (PDIV) [20]. Nevertheless, the voltage value of $300 \mathrm{Vrms}$, which guarantees no PDs at ground level, might not ensure PD-free operations in aerospace environment. Indeed, based on Paschen's law, the voltage necessary to incept a discharge between two electrodes at fixed distance, decreases at low pressure. This aspect is crucial in electrical devices for aerospace applications, because high altitude corresponds to lower ambient pressure with respect to sea level. Consequently, the voltage level should be carefully chosen for avoiding the inception of PDs, which can cause the premature insulation breakdown. As the analysed drive operates with a DC link of $270 \mathrm{~V}$ and the PEC is connected to the PMSM through a short feeder cable, according to IEC 60034-18-41 [20], then there is no risk of PDs inception. In case of higher DC link voltage and/or faster switching devices (e.g. silicon carbide MOSFET), the end of life criterion adopted in the presented investigation (i.e. AC Hipot test) might result inappropriate. Mechanical stresses, such as vibrations, represent a typical aging factor in transportation applications [36]. According to the experience gained during the test campaign, it is observed that the insulation coating becomes brittle after few days of thermal cycling above its thermal class. Hence, mechanical vibrations and/or shocks might lead to the enamel detachment exposing the conductive material of the magnet wire. For this reason, precautions should be taken at design and manufacturing stages of the EM, for minimising and/or preventing the enamel detachment e.g. using silicone-based varnishes.

\section{CONCLUSIONS}

This paper presented an experimental investigation on the thermal aging of low voltage random wound coils, with a short duty cycle aerospace PM machine acting as a case study. A new lifetime model (based on Arrhenius and Miner laws) was proposed and validated. The outcomes provided by the proposed lifetime model allow to assert that the PMSM can withstand 53,689 thermally-overloaded activations before having a turn to turn failure caused by thermal aging. For the considered EMA, the obtained value corresponds to a number of flights higher than 26,000.

All this highlights the worth of the proposed model. While the described processes and lifetime model have been used for the application at hand, it is important to underline that the 
model introduced here is applicable for all short duty cycle EMs that adopt similar winding systems (i.e. random wound EMs).

From the performed accelerated aging tests, it was verified that the insulation lifetime of low voltage EMs halves for every $\approx 7{ }^{\circ} \mathrm{C}$ temperature increment, even in dynamic temperature operations above the thermal class. Furthermore, it was confirmed that the turn to turn insulation is the weakest insulation subsystem in a low voltage EM.

One of the main objectives of the presented study consists in including insulation physics of failure aspects in the design processes of electrical machines. In this work, it has been shown that a thorough knowledge of insulation degradation mechanisms can eliminate the need for over-engineering. In many cases, electrical machines are over-dimensioned in order to keep a "safety-margin". This can be removed by the use of physics of failure methodologies, which become even more effective if they are considered at all stages of the design process. This implies that with these methodologies, then, the same mission profile can be fulfilled with a smaller and lighter machine, which is a very attractive feature for aerospace applications.

The model here can then be developed further to achieve a comprehensive lifetime model that combines and considers the effects of thermal, electrical, mechanical and environmental aging on the insulation lifetime. This is going to be examined as the next steps of the presented work.

\section{REFERENCES}

[1] B. Sarlioglu and C. T. Morris, "More Electric Aircraft: Review, Challenges, and Opportunities for Commercial Transport Aircraft," IEEE Transactions on Transportation Electrification, vol. 1, no. 1, pp. 54-64, 2015.

[2] V. Madonna, P. Giangrande, and M. Galea, "Electrical Power Generation in Aircraft: Review, Challenges, and Opportunities," IEEE Transactions on Transportation Electrification, vol. 4, no. 3, pp. 646-659, 2018.

[3] A. Boglietti, A. Cavagnino, A. Tenconi, and S. Vaschetto, "The safety critical electric machines and drives in the more electric aircraft: A survey," in 2009 35th Annual Conference of IEEE Industrial Electronics, 2009, pp. 2587-2594.

[4] W. Cao, B. C. Mecrow, G. J. Atkinson, J. W. Bennett, and D. J. Atkinson, "Overview of Electric Motor Technologies Used for More Electric Aircraft (MEA)," IEEE Transactions on Industrial Electronics, vol. 59, no. 9, pp. 3523-3531, 2012.

[5] J. W. Bennet, "Fault tolerant electromechanical actuators for aircraft," $\mathrm{PhD}$, Newcastle University, http://hdl.handle.net/10443/990, 2010.

[6] G. Qiao, G. Liu, Z. Shi, Y. Wang, S. Ma, and T. C. Lim, "A review of electromechanical actuators for More/All Electric aircraft systems," Proceedings of the Institution of Mechanical Engineers, Part C: Journal of Mechanical Engineering Science, vol. 0, no. 0, p. 0954406217749869.

[7] M. Galea, C. Gerada, T. Raminosoa, and P. Wheeler, "A Thermal Improvement Technique for the Phase Windings of Electrical Machines," IEEE Transactions on Industry Applications, vol. 48, no. 1, pp. 79-87, 2012.

[8] V. Madonna, A. Walker, P. Giangrande, C. Gerada, G. Serra, and M. Galea, "Improved thermal management and analysis for stator endwindings of electrical machines," IEEE Transactions on Industrial Electronics, Vol. 66, no. 7, pp. 5057-5069, 2018.

[9] V. Madonna, P. Giangrande, A. Walker, and M. Galea, "On the Effects of Advanced End-Winding Cooling on the Design and Performance of Electrical Machines," in 2018 XIII International Conference on Electrical Machines (ICEM), 2018, pp. 311-317.

[10] C. Sciascera, M. Galea, P. Giangrande, and C. Gerada, "Lifetime consumption and degradation analysis of the winding insulation of electrical machines," in 8th IET International Conference on Power Electronics, Machines and Drives (PEMD 2016), 2016, pp. 1-5.

[11] V. M. Montsinger, "Loading Transformers By Temperature," Transactions of the American Institute of Electrical Engineers, vol. 49, no. 2, pp. 776-790, 1930.
[12] T. W. Dakin, "Electrical Insulation Deterioration Treated as a Chemical Rate Phenomenon," Transactions of the American Institute of Electrical Engineers, vol. 67, no. 1, pp. 113-122, 1948.

[13] G. C. Montanari and L. Simoni, "Aging phenomenology and modeling," IEEE Transactions on Electrical Insulation, vol. 28, no. 5, pp. 755-776, 1993.

[14] S. Grubic, J. M. Aller, B. Lu, and T. G. Habetler, "A Survey on Testing and Monitoring Methods for Stator Insulation Systems of Low-Voltage Induction Machines Focusing on Turn Insulation Problems," IEEE Transactions on Industrial Electronics, vol. 55, no. 12, pp. 4127-4136, 2008.

[15] P. Giangrande, V. Madonna, G. Sala, A. Kladas, C. Gerada, and M. Galea, "Design and Testing of PMSM for Aerospace EMA Applications," presented at the 2018 Annual Conference of the IEEE Industrial Electronics Society - IECON 2018, Washington DC, 2018.

[16] R. Rothe and K. Hameyer, "Life expectancy calculation for electric vehicle traction motors regarding dynamic temperature and driving cycles," in 2011 IEEE International Electric Machines \& Drives Conference (IEMDC), 2011, pp. 1306-1309.

[17] E. L. Brancato, "Estimation of lifetime expectancies of motors," IEEE Electrical Insulation Magazine, vol. 8, no. 3, pp. 5-13, 1992.

[18] G. Mazzanti, "Analysis of the Combined Effects of Load Cycling, Thermal Transients, and Electrothermal Stress on Life Expectancy of High-Voltage AC Cables," IEEE Transactions on Power Delivery, vol. 22, no. 4, pp. 2000-2009, 2007.

[19] C. Sciascera, P. Giangrande, C. Brunson, M. Galea, and C. Gerada, "Optimal design of an electro-mechanical actuator for aerospace application," in IECON 2015 - 41st Annual Conference of the IEEE Industrial Electronics Society, 2015, pp. 001903-001908.

[20] IEC 60034-18-41:2014 Rotating electrical machines - Part 18-41: Partial discharge free electrical insulation systems (Type I) used in rotating electrical machines fed from voltage converters - Qualification and quality control tests 2014.

[21] P. Giangrande, V. Madonna, S. Nuzzo, and M. Galea, "Design of FaultTolerant Dual Three-Phase Winding PMSM for Helicopter Landing Gear EMA," presented at the 2018 IEEE ESARS-ITEC, Nottingham UK, 2018

[22] H. Zhe, "Modeling and Testing of Insulation Degradation due to Dynamic Thermal Loading of Electrical Machines," PhD, Lund University, 2017.

[23] V. Madonna, P. Giangrande, C. Gerada, and M. Galea, "Thermal analysis of fault-tolerant electrical machines for aerospace actuators," IET Electric Power Applications, 2018.

[24] C. Sciascera, P. Giangrande, L. Papini, C. Gerada, and M. Galea, "Analytical Thermal Model for Fast Stator Winding Temperature Prediction," IEEE Transactions on Industrial Electronics, vol. 64, no. 8, pp. 6116-6126, 2017.

[25] W. Li and J. Fielding, "Preliminary study of EMA landing gear actuation," in Proc. 28th Int. Congress of the Aeronautical Sciences, Brisbane, Australia, 2012, pp. 23-28.

[26] S. J. Williamson, R. Wrobel, J. Yon, J. D. Booker, and P. H. Mellor, "Investigation of equivalent stator-winding thermal resistance during insulation system ageing," in 2017 IEEE 11th International Symposium on Diagnostics for Electrical Machines, Power Electronics and Drives (SDEMPED), 2017, pp. 550-556.

[27] G. C. Stone, I. Culbert, E. A. Boulter, and H. Dhirani, Electrical Insulation for Rotating Machines: Design, Evaluation, Aging, Testing, and Repair. Wiley, 2014.

[28] L. Simoni, "A General Approach to the Endurance of Electrical Insulation under Temperature and Voltage," IEEE Transactions on Electrical Insulation, vol. EI-16, no. 4, pp. 277-289, 1981.

[29] C. R. Paul, Introduction to electromagnetic compatibility. John Wiley \& Sons, 2006.

[30] IEC 60172:2015 Test procedure for the determination of the temperature index of enamelled and tape wrapped winding wires, 2015.

[31] "IEEE Recommended Practice for Measurement of Power Factor Tip-Up of Electric Machinery Stator Coil Insulation," IEEE Std 286-2000, pp. i29, 2001.

[32] J. W. Bennett, B. C. Mecrow, A. G. Jack, and D. J. Atkinson, "A Prototype Electrical Actuator for Aircraft Flaps," IEEE Transactions on Industry Applications, vol. 46, no. 3, pp. 915-921, 2010.

[33] DuPont, "Nomex 410 Technical Data Sheet," ed, 2016.

[34] A. Cavallini, D. Fabiani, and G. C. Montanari, "Power electronics and electrical insulation systems - Part 3: Diagnostic properties," IEEE Electrical Insulation Magazine, vol. 26, no. 5, pp. 30-40, 2010. 
[35] H. Okubo, N. Hayakawa, and G. C. Montanari, "Technical Development on Partial Discharge Measurement and Electrical Insulation Techniques for Low Voltage Motors Driven by Voltage Inverters," IEEE Transactions on Dielectrics and Electrical Insulation, vol. 14, no. 6, pp. 1516-1530, 2007.

[36] P. Mancinelli, S. Stagnitta, and A. Cavallini, "Qualification of Hairpin Motors Insulation for Automotive Applications," IEEE Transactions on Industry Applications, vol. 53, no. 3, pp. 3110-3118, 2017.

[37] F. N. Nwobi and C. A. Ugomma, "A comparison of methods for the estimation of Weibull distribution parameters," Metodoloski zvezki, vol. 11, no. 1, p. 65, 2014.

[38] M. Rottach, "Drive-system optimisation for a helicopter electromecanical actuation system," PhD, University of Nottingham, 2014.

[39] P. Giangrande, A. Al-Timimy, A. Galassini, S. Papadopoulos, M. Degano, and M. Galea, "Design of PMSM for EMA Employed in Secondary Flight Control Systems," in 2018 IEEE ESARS-ITEC, 2018, pp. 1-6.

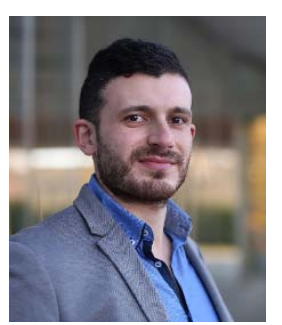

Vincenzo Madonna (S'17) received the BSc degree in Electronic Engineering from the University of Calabria, Italy, in 2012, and the MSc degree in Electrical Engineering from the University of Bologna, Italy, in 2016. In 2012 he was an Exchange Student at KU Leuven, Belgium, and in 2015 he was a Visiting Researcher at the University of Nottingham, UK. He is currently a Marie Curie Fellow and $\mathrm{PhD}$ candidate in electrical machines design within the Institute for Aerospace Technology (IAT) and the PEMC group at the University of Nottingham, UK. His research interests include design, thermal management and lifetime prediction modelling of electrical machines. Mr. Madonna received the qualification of Italian Chartered Engineer in 2016. He serves as a reviewer for the IEEE TRANS. ON INDUSTRIAL ELECTRONICS, TRANSPORTATION ELECTRIFICATION and various IEEE-sponsored International Conferences.

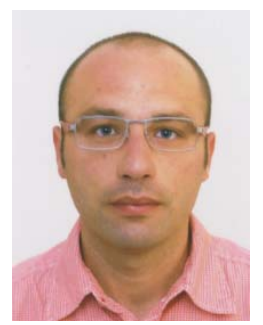

Paolo Giangrande (M'12) received the Bachelor's (Hons.) and Master's (Hons.) degrees in electrical engineering at the Politecnico of Bari in 2005 and 2008, respectively. During 2008, he was a Marie Curie Intra-European Fellow at the University of Malta. He received his $\mathrm{PhD}$ in electrical engineering at the Politecnico of Bari in 2011. Since January 2012, he is Research Fellow at the University of Nottingham (UK), within the Power Electronics, Machines and Control Group. From 2017, he is the head of the Accelerated Lifetime Testing Laboratory at the Institute of Aerospace Technology, Nottingham. His main research interests include sensorless control of AC electric drives, design and testing of electromechanical actuators for aerospace, thermal management of highperformance electric drives and reliability and lifetime modelling of electrical machines.

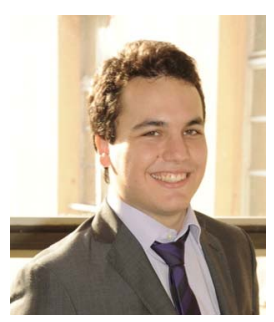

Luca Lusuardi (S'17) was born on 16 September 1991. In March 2016 he received the M.S. degree in energy and nuclear enegineering from the University of Bologna (Italy), where is currently pursuing the $\mathrm{Ph} . \mathrm{D}$. degree in biomedical, electrical and systems engineering. In June 2017 he joined IEEE Dielectrics and Electrical Insulation Society. His research interests are diagnosis of insulation systems by partial discharge analysis, the study of the ageing mechanisms of rotating electrical machines and reliability of inverter-fed low voltage motors, especially in the aeronautical and automotive fields.

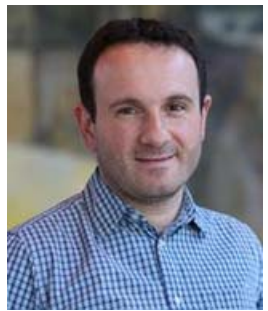

Chris Gerada (M'05-SM'12) received the Ph.D. degree in numerical modelling of electrical machines from The University of Nottingham, Nottingham, U.K., in 2005. He subsequently worked as a Researcher with The University of Nottingham on high-performance electrical drives and on the design and modelling of electromagnetic actuators for aerospace applications. In 2008, he was appointed as a Lecturer in electrical machines; in 2011, as an Associate Professor; and in 2013, as a Professor at The University of Nottingham. He was awarded a Research Chair from the Royal Academy of Engineering in 2013 and his main research interests include the design and modelling of high-performance electric drives and machines. Prof. Gerada serves as an Associate Editor for the IEEE TRANSACTIONS ON INDUSTRY APPLICATIONS and is the past Chair of the IEEE IES Electrical Machines Committee.
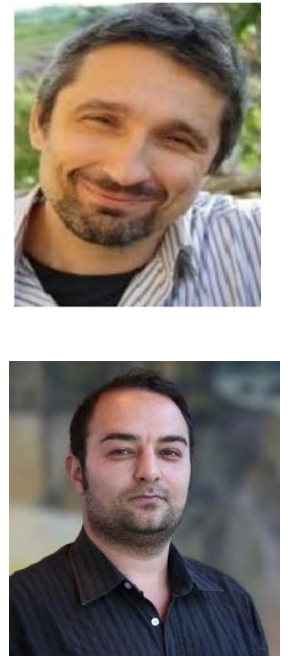

Andrea Cavallini (M'95) was born on December 21, 1963. He received from the University of Bologna the Master degree in electrical engineering in 1990 and the Ph.D. degree in electrical engineering in 1995. He was a researcher at Ferrara University from 1995 to 1998. Since 1998, he is an Associate Professor at Bologna University. His research interests are: diagnosis of insulation systems by partial discharge analysis, reliability of electrical systems and artificial intelligence..

Michael Galea (M'13-SM'18, FRAeS) received his $\mathrm{PhD}$ in electrical machines design from the University of Nottingham, UK, where he has also worked as a Research Fellow. He is currently the Head of School of Aerospace in the University of Nottingham, Ningbo, China, where he is also the Director of Aerospace. He currently lectures in Electrical Drives and in Aerospace Systems Integration and manages a number of diverse projects and programmes related to the more / all electric aircraft, electrified propulsion and associated fields. His main research interests are design, analysis and thermal management of electrical machines and drives (classical and unconventional), the more electric aircraft and electrified and hybrid propulsion. He is a Fellow of the Royal Aeronautical Society and a Senior Member of the IEEE. 